\title{
Use of Contraceptive among Postpartum Women of a Municipality: A Descriptive Cross-sectional Study
}

\author{
Mukta Singh Bhandari, ${ }^{1}$ Suresh Kayastha² \\ 'Department of Community Medicine, Kathmandu University School of Medical Sciences, Dhulikhel, \\ Kavrepalanchok, Nepal, ${ }^{2}$ Department of Obstetrics and Gynaecology, Nepal Korea Friendship Municipality \\ Hospital, Balkumari, Thimi, Bhaktapur, Nepal.
}

\section{ABSTRACT}

Introduction: Contraception plays a key role in preventing unwanted births. It also decreases the pregnancy and childbirth-related morbidities and mortalities, but many women don't use contraception particularly in the postpartum period. The main objective of this study was to find out the prevalence of contraception use among postpartum women in a municipality.

Methods: A descriptive cross-sectional study was conducted among married women of reproductive age in Dhulikhel municipality of Kavrepalanchok from January to September 2019. Ethical approval was obtained from Institutional Review Committee and permission was taken from Dhulikhel Municipality before the study. The sample size was 332. A convenience sampling method was used. A semi-structured questionnaire pre-tested in Panauti municipality was used. Data entry and analysis were done using Statistical Package for Social Sciences version 20. Point estimate at 95\% Confidence Interval was calculated for descriptive analysis.

Results: Out of total 332 women, 146 (40\%) (34.73-45.26 at 95\% Confidence Interval) used postpartum contraception. Injectable/Depot was used by 61 (42\%) women. Total 97 (52\%) of the non-users intended to use contraception in the future. The most common reason for contraception use was women not wanting the next child soon 91 (62\%) and reason for non-use was feeling contraception as unnecessary $73(39 \%)$.

Conclusions: The use of postpartum contraception was poor, and only half of the non-users intended to use contraception in the future. Thus, contraception use should be encouraged during all possible contact times, and counselling should be made universal to improve postpartum contraception services' uptake.

Keywords: contraception; contraceptive devices; postpartum period.

\section{INTRODUCTION}

Contraceptive leads to reduction in unplanned pregnancies and also improves maternal and child wellbeing. Contraception also helps to empower women by giving more choice over fertility and gives opportunities for education and career development. ${ }^{1-5}$

Despite many programs of Nepal focusing on family planning, $24 \%$ of women have unmet need for contraception and $21 \%$ of births take place before the recommended twenty four months interval. ${ }^{6}$ Also, very less information on postpartum contraception use is known about Dhulikhel municipality.
Thus, this study aims to find out the prevalence of postpartum contraception use among women living in Dhulikhel municipality of Kavrepalanchok.

\section{METHODS}

A descriptive cross-sectional study was done at Dhulikhel municipality of Kavrepalanchok district of Nepal. The duration of study was from January 2019

Correspondence: Dr. Mukta Singh Bhandari, Department of Community Medicine, Kathmandu University School of Medical Sciences, Dhulikhel, Kavrepalanchok, Nepal. Email: me_mukta@hotmail.com, Phone: +977-9841383826. 
to September 2019. Ethical approval was taken from Institutional Review Committee of Dhulikhel Hospital (Reference number 123/18) and permission to conduct study was taken from Dhulikhel municipality (Reference number 221). After explaining the objective of the study in detail, verbal consent was taken from each respondent. Women below the age of 49 years who had given birth within 6 weeks up to three years prior to the survey were included in the study. However, those women having still birth, neonatal or infant mortality or having any contraindication for contraceptive use were excluded from the study.

The sample size was calculated using the given formula.

$$
\begin{aligned}
\mathrm{n} & =\mathrm{Z}^{2} \times \mathrm{p} \times \mathrm{q} / \mathrm{e}^{2} \\
& =(1.96)^{2} \times(0.27) \times(1-0.27) /(0.05)^{2} \\
& =302 \\
\text { Where, } & \\
\mathrm{n} & =\text { the sample size } \\
\mathrm{Z} & =1.96 \text { at } 95 \% \text { Confidence Interval } \\
\mathrm{p} & =\text { prevalence of postpartum contraception use, } 27 \% 7 \\
\mathrm{q} & =1-\mathrm{p} \\
\mathrm{e} & =\text { margin of error, } 5 \%
\end{aligned}
$$

After taking the non-response rate of $10 \%$ the final sample size was 322 .

Five enumerators from medical and public health background were oriented before data collection. Data was collected using semi-structured questionnaire which was pre-tested at ward number five of Panauti municipality before the survey. Necessary modifications were done in the questionnaire before the actual study.

There are 12 wards in Dhulikhel municipality. Out of 12 wards, six wards i.e., ward number 1, 3, 4, 7, 9 and 11 were selected by probability proportion to size method. Household was considered as one unit and number of households in each ward were selected by proportion which gave the sample size of $38,46,67,59,56$ and 66 in the above wards respectively. As many of the households didn't have eligible women and many households were empty during preliminary survey, convenience sampling method was used for the final data collection. One woman from each household was approached and if more than one eligible woman were present in a household, then the one with youngest child was selected. Households were taken until sample size was fulfilled.

A descriptive analysis of socio-demographic variables was done using mean, frequency, percentage and standard deviation. Data entry and analysis was done in Statistical Package for Social Sciences (SPSS) version 20.

\section{RESULTS}

Out of total 332 women, 146 (44\%) were using postpartum contraception at present which included all forms of contraception i.e., modern or natural methods.

The mean age of women was $26.21 \pm 4.27$ years

\begin{tabular}{|c|c|c|}
\hline \multicolumn{2}{|c|}{ Socio-demographic variables } & n (\%) \\
\hline \multirow[t]{3}{*}{ Religion } & Hindu & $260(78)$ \\
\hline & Buddhist & $51(15)$ \\
\hline & $\begin{array}{l}\text { Christian and } \\
\text { others }\end{array}$ & $21(7)$ \\
\hline \multirow[t]{4}{*}{ Caste } & Chhetri & $69(21)$ \\
\hline & Brahmin & $64(19)$ \\
\hline & Janajati & $172(52)$ \\
\hline & Others & $27(8)$ \\
\hline \multirow[t]{4}{*}{ Education } & Illiterate & $13(4)$ \\
\hline & Literate & $9(3)$ \\
\hline & Up to SLC & $167(50)$ \\
\hline & Above SLC & $143(43)$ \\
\hline \multirow{5}{*}{$\begin{array}{l}\text { Occupation of } \\
\text { women }\end{array}$} & Farming & $50(15)$ \\
\hline & Job & $48(14)$ \\
\hline & Home maker & $173(52)$ \\
\hline & Business & $42(13)$ \\
\hline & $\begin{array}{l}\text { Student and } \\
\text { others }\end{array}$ & $19(6)$ \\
\hline \multirow[t]{2}{*}{ Type of family } & Nuclear & $152(46)$ \\
\hline & Joint & $180(54)$ \\
\hline \multirow[t]{2}{*}{ Mass media exposure } & Yes & $299(90)$ \\
\hline & No & $33(10)$ \\
\hline \multirow[t]{2}{*}{ Place of last birth } & Health facility & $310(93)$ \\
\hline & Home & $22(7)$ \\
\hline \multirow[t]{2}{*}{ Type of birth } & Normal & $246(74)$ \\
\hline & Cesarean section & $86(26)$ \\
\hline
\end{tabular}
(Mean \pm SD). Total 260 (78\%) women were Hindu and Janajati 172 (52\%) by caste. Total 167 (50\%) women had education up to SLC and 173 (52\%) were home makers. Most of the women 180 (54\%) lived in joint family and 299 (90\%) had mass media exposure regarding contraceptive methods. Total 310 (93\%) women had delivered in a health facility and 246 (74\%) had normal delivery (Table 1 ).

Total 260 (78\%) women have had resumption of menorrhea and the mean duration of amenorrhea was $5.9 \pm 3.77$ months (Mean \pm SD). Out of 260 women who had resumption of menorrhea, 43 (16.5\%) had resumption in less than three months, $93(36 \%)$ in 3 to 6 months while 124 (48\%) had resumption in greater than 6 months duration.

Around 41 (12\%) women gave history of ever having unwanted pregnancy but none of them responded to have aborted the unwanted conception.

Total 117 (35\%) women reported to have used any contraceptive method in the past and out of them, 49 $(42 \%)$ reported to have had adverse effect with 20 women (41\%) experiencing bleeding problem, 15 (31\%) 
irregular cycle, $8(16 \%)$ weight gain and $5(12 \%)$ others which included weight loss $2(4 \%)$, amenorrhea 2 (4\%) and pain abdomen 1 (3\%).

Out of total 332 women, $158(48 \%)$ said that they know about postpartum contraceptive methods but only $119(75 \%)$ out of them could correctly list at least two names of postpartum contraceptive methods (Figure 1).

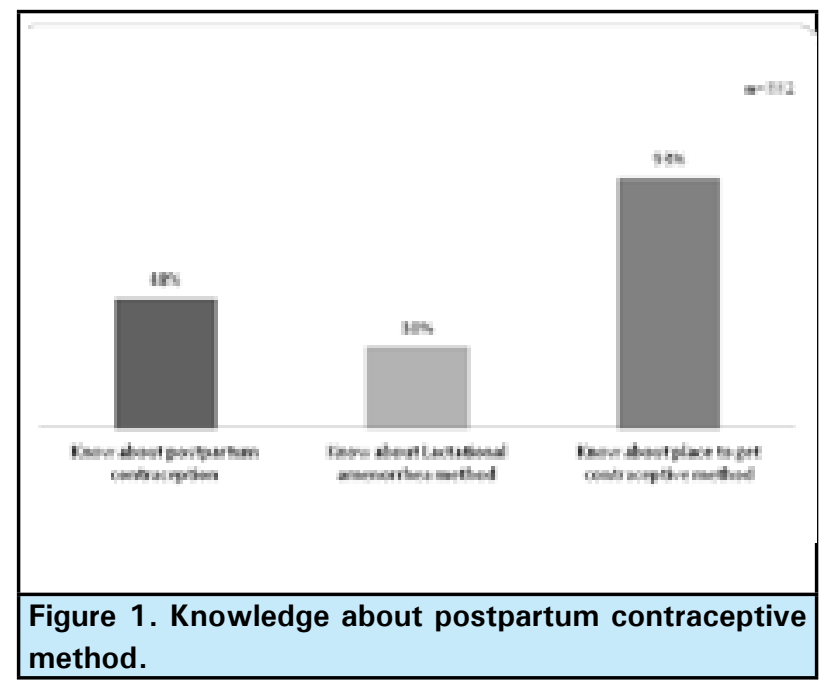

Among 310 women who had given birth in a health facility, 237 (76\%) received counseling regarding postpartum contraception while only 177 (57\%) received counseling regarding adverse effects of contraceptive methods following delivery. Total 150 (63\%) women reported having being counseled by nurses, $77(32 \%)$ by doctors and $10(5 \%)$ by nursing students. Likewise, only 100 (30\%) women out of 332 reported to have received counseling regarding postpartum contraception during immunization of their child.

Out of 332 women, total 146 (44\%) women reported to be using any form of postpartum contraception and most commonly reported method of contraception was Depot 61 (42\%) while use of long acting reversible contraceptive method (LARC) was 50 (34\%) (Figure 2).

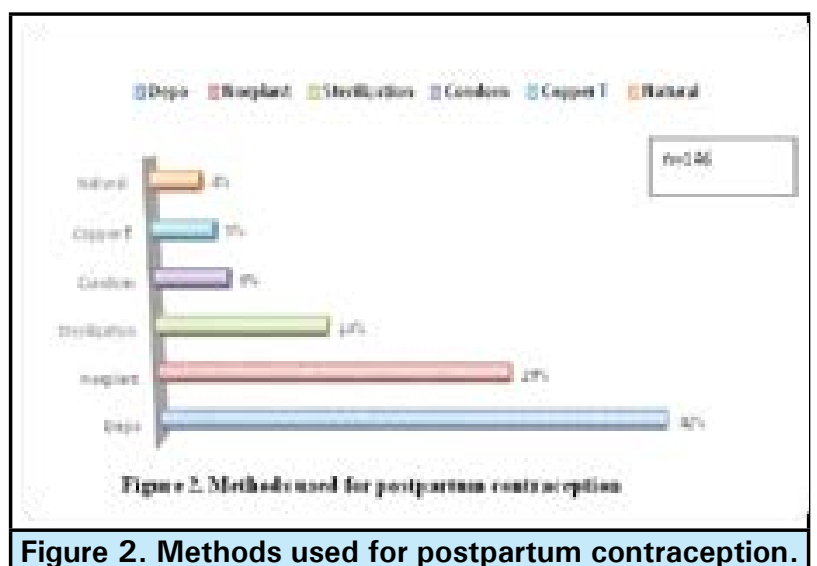

Among contraceptive users, 91 (62\%) women said that the reason for using contraception was not wanting another child soon while $4(3 \%)$ said that they were advised by health worker and one $(1 \%)$ said that she was advised by family member. Total 219 (66\%) women said that decision of contraceptive use is jointly made by them along with husband while 63 (19\%) reported making decision by themselves and 50 (15\%) by husband.

Out of 332 women, 186 (56.02\%) were non-users and 73 (39\%) women among them stated using contraception as being unnecessary while 4 (2\%) gave other reasons which were unavailability of intended method and current pregnancy (Figure 3).

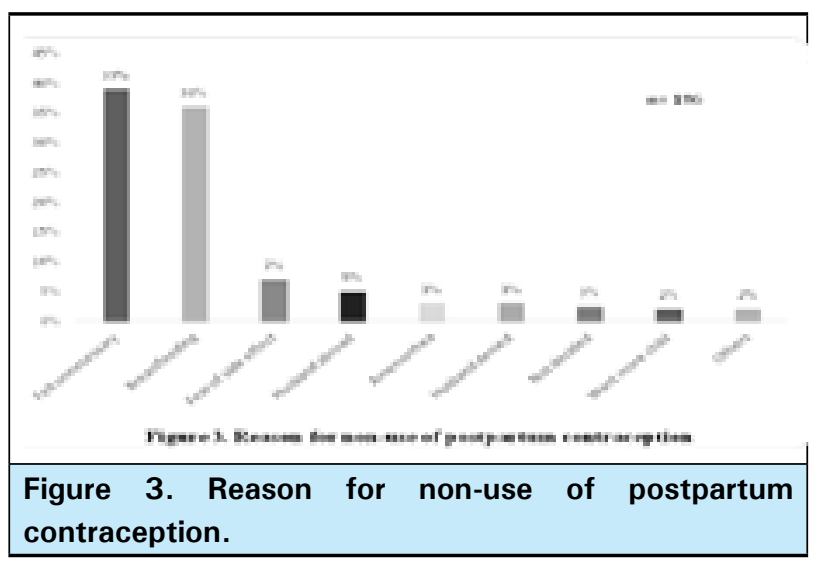

Out of 186 non-users, 102 (54.83\%) women didn't use contraception but also didn't want any child soon due to various reasons thus giving the unmet need of 57 (31\%) among study group.

Out of 186 postpartum contraception non-users, 97 $(52 \%)$ intended to use some form of contraception in the future and the contraceptive of choice were Norplant, sterilization and Depot reported by 20 (20\%), $13(13 \%)$, and $13(13 \%)$ women respectively while 41 $(42 \%)$ women said that they don't know what method they intended to use.

\section{DISCUSSION}

The use of postpartum contraception in this study was poor and only some women had intention to use contraception in the future. Although counseling about contraception was done, women were not informed about the side effects of contraceptive methods.

The result of this study indicates poor utilization of postpartum contraception which is in line with studies done in $\mathrm{Nepal}^{8,9}$ and also studies from Bangladesh ${ }^{10}$ and Ethiopia ${ }^{11-13}$ showing utilization below $50 \%$. But higher uses of postpartum contraception were found in Kenya $^{14}(86 \%)$ and Liberia ${ }^{15}$ (77\%) which may be due to more acceptability and accessibility to contraceptive 
services in those places.

The most common method of contraception used by women in this study was found to be injectable method or Depot which is similar to many studies done in Nepal, ${ }^{9,16,17}$ Ethiopia, ${ }^{11-13,18}$ Kenya $^{14}$ which may be due to the easy accessibility, availability, less effect on lactation and ease of administration.

This study found that only around half of the postpartum contraception non-users intended to use any form of contraception in the future. This finding is consistent with findings from studies Nepal ${ }^{9,16,17}$ but very high intention to use was found in other parts of the world like Bangladesh ${ }^{10}$ Ethiopia ${ }^{19}$ and Ohio. ${ }^{20}$ The difference in socio-demographic structure, awareness, availability of services might have affected the intention of women to use postpartum contraception in the future.

Women who knew about postpartum contraception was below $50 \%$ which is similar to study from Kailali ${ }^{8}$ $(42 \%)$ but higher proportion of women knew about it in Liberia $^{15}(79 \%)$ and Indonesia (77\%). ${ }^{21}$

Our study showed that current non-users of contraception intended to use long term method or permanent method compared to those who were already using any method of contraception which is consistent to findings from Ohio $^{20}$ and Nigeria. ${ }^{22}$

Most common reason stated for not using any postpartum contraception in this study were feeling it as unnecessary and amenorrhea which were also seen in study done in Kailali, ${ }^{8}$ Ethiopia, ${ }^{10-13}$ and Egypt. ${ }^{23}$

Counseling regarding postpartum contraception was received by 3/4th of the women which is similar with other studies from Nepal.9,16 But the Nepal Demographic Health Survey showed $13 \%$ counseling in the postpartum period in the country, which might be due to the difference between service provider and coverage between different sectors. ${ }^{6}$ As the main service provider in our study was tertiary level teaching hospital, the service coverage might have been greater than the national data.

This study had certain limitations. Being a crosssectional study, the study could not explore more about the women's experience and reasons for utilization or non-utilization of postpartum contraception. Due to lack of feasibility and cost, the study participants couldn't be randomly selected at household level. As the study was done in different wards of Dhulikhel municipality, it doesn't represent whole of Kavrepalanchok or Nepal.

\section{CONCLUSIONS}

The use of postpartum contraception was poor and knowledge about postpartum contraceptive devices was also not good. Women didn't feel the need of contraception; thus, counseling should be made universal at all contact periods starting from pregnancy.

\section{ACKNOWLEDGEMENTS}

We would like to acknowledge the data collectors for their hard work. We are grateful towards the respondents for their valuable time and response. We would also like to thank Dhulikhel Municipality for their co-operation.

Conflict of Interest: None.

\section{REFERENCES}

1. World Health Organization. Family planning/contraception methods [Internet]. Geneva: World Health Organization; 2020 Jun 22 [cited 2020 Oct 9]. Available from: http:// www.who.int/news-room/fact-sheets/detail/family-planning-contraception. [Full Text]

2. FHI 360. Postpartum family planning new research findings and program implications [Internet]. North Carolina (US): FHI 360; 2012 [cited 2020 Oct 10]. Available from: https:// www.fhi360.org/sites/default/files/media/documents/ Postpartum\%20Family\%20Planning.pdf. [Full Text]

3. Ahmed S, Li Q, Liu L, Tsui AO. Maternal deaths averted by contraceptive use: an analysis of 172 countries. Lancet. Elsevier; 2012 Jul 14;380(9837):111-25. [uuMed | Full Text I DOI]

4. Mahande MJ, Obure J. Effect of interpregnancy interval on adverse pregnancy outcomes in northern Tanzania : a registry-based retrospective cohort study. BMC Pregnancy Childbirth. 2016;16(1):140. [PubMed | Full Text | DOI]

5. Class QA, Rickert ME, Oberg AS, Sujan AC, Almqvist C,
Larsson $\mathrm{H}$, et al. Within-family analysis of interpregnancy interval and adverse birth outcomes. Obstet Gynecol. 2017 Dec;130(6):1304-11. [uuㄹ | Full Text | DOI]

6. Department of Health Services. Nepal demographic and health survey 2015 [Internet]. Kathmandu (NP): Department of Health Services; 2017 Nov [cited 2020 Oct 10]. Available from: https://www.dhsprogram.com/pubs/pdf/fr336/ fr336.pdf. [Full Text]

7. Department of Health Services. National family planning costed implementation plan 2015-2020 [Internet]. Kathmandu (NP): Department of Health Services; 2015 [cited 2020 Oct 11]. Available from: https://nepal.unfpa. org/.../national-family-planning-costed-implementation-plan-2015. [Full Text]

8. Joshi AK, Tiwari DP, Poudyal A, Shrestha N, Acharya U, Dhungana GP. Utilization of family planning methods among postpartum mothers in Kailali District, Nepal. Int J Women's Health. 2020;12:487-94. [PubMed | Full Text | $\underline{\mathrm{DOI}}]$ 
Bhandari et al. Use of Contraceptive among Postpartum Women of a Municipality: A Descriptive Cross-sectional Study...

9. Shrestha S, Poudel R, Napit J. Awareness and practice on postpartum family planning among postpartum mothers attending on maternal and child health clinic. JCMS-Nepal. 2020;16(2):88-92. [Full Text | DOI]

10. Tazneen J, Hamid S, Rahman M. Unmet Need of Postpartum Contraceptives Use in Urban Slums. J Prev Social Med. 2020;38(2):46-52. [Full Text | DOI]

11. Abraha TH, Teferra AS, Gelagay AA. Postpartum modern contraceptive use in northern Ethiopia: prevalence and associated factors. Epidemiol Health. 2017 Mar 20;39:e2017012. [uuMed | Full Text | DOI]

12. Berta M, Feleke A, Abate T, Worku T, Gebrecherkos T. utilization and associated factors of modern contraceptives during extended postpartum period among women who gave birth in the last 12 months in Gondar Town, Northwest Ethiopia. Ethiop J Health Sci. 2018 Mar;28(2):207-16. [PubMed | Full Text $\mid \underline{\text { DOI] }}$

13. Demie TG, Demissew T, Huluka TK, Workineh D, Libanos HG. Postpartum family planning utilization among postpartum women in public health institutions of Debre Berhan Town, Ethiopia. J Women's Health Care. 2018;7(2):1-9. [ Full Text | DOI]

14. Jalang OR, Thuita F, Barasa SO, Njoroge P. Determinants of contraceptive use among postpartum women in a county hospital in rural Kenya. BMC Public Health. 2017;17(1):1-8. [ PubMed $\mid$ Full Text $\mid \underline{\text { DOI] }}$

15. Kaydor VK, Adeoye IA, Olowolafe TA, Adekunle AO. Barriers to acceptance of post-partum family planning among women in Montserrado County, Liberia. Niger Postgrad Med J. 2018 Jul-Sep;25(3):143-8. [릴ed | Full Text | DOI]

16. Thapa K, Dhital R, Rajbhandari S, Thapa S, Pokhrel S, Mishra $\mathrm{S}$, et al. Prevalence of postpartum family planning service coverage in selected referral facilities of Nepal. JNMA J
Nepal Med Assoc. 2020 Jan;58(221):1-5. [ [PubMed | Full Text I DOI]

17. Bajracharya A. Knowledge, attitude, and practice of contraception among postpartum women attending Kathmandu Medical College Teaching Hospital. Kathmandu Univ Med J (KUMJ). 2015 Oct-Dec;13(52):292-7. [라bMed | Full Text $\mid \underline{\text { DOI] }}$

18. Tegegn M, Arefaynie M, Tiruye TY. Unmet need for modern contraceptives and associated factors among women in the extended postpartum period in Dessie town, Ethiopia. Contracept Reprod Med. 2017 Aug 7;2:21. [ㅁuMed | Full Text | DOI]

19. Abraha TH, Belay HS, Welay GM. Intentions on contraception use and its associated factors among postpartum women in Aksum town, Tigray region, northern Ethiopia: a community-based cross- sectional study. Reprod Health. 2018 Nov 9;15(1):188. [

20. Loewenberg Weisband Y, Keder LM, Keim SA, Gallo MF. Postpartum intentions on contraception use and method choice among breastfeeding women attending a university hospital in Ohio: a cross-sectional study. Reprod Health. 2017 Mar 20;14(1):45. [라Med | Full Text | DOI]

21. Humairah G, Jusuf EC, Humairah G. Factors influencing postpartum contraceptive utilization at the Siti Fatimah mother and child hospital Makassar. Nusantara Medical Science Journal. 2018;3(1):1-7. [ [Full Text | DOI]

22. Ujah OI, Ocheke AN, Mutihir JT, Okopi JA, Ujah IAO. Postpartum contraception: determinants of intention and methods of use among an obstetric cohort in a tertiary hospital in Jos, North Central Nigeria. Int J Rep Contacept Obstet Gynecol. 2017;6(12):5213-8. [Full Text | DOI]

23. Elweshahi HMT, Gewaifel GI, Sadek SSE-D, El-Sharkawy OG. Unmet need for postpartum family planning in Alexandria, Egypt. Alexandria J Med. 2018;54(2):143-7. [ [Full Text | DOI]

This work is licensed under a Creative Commons Attribution 4.0 International License. The images or other third party material in this article are included in the article's Creative Commons license, unless indicated otherwise in the credit line; if the material is not included under the Creative Commons license, users will need to obtain permission from the license holder to reproduce the material. To view a copy of this license, visit http://creativecommons.org/licenses/by/4.0/ 